\title{
O IMPACTO DOS EFEITOS DA OCUPAÇÃO SOBRE A SAÚDE DE TRABALHADORES. I. MORBIDADE
}

René Mendes*

\begin{abstract}
MENDES, R. O impacto dos efeitos da ocupação sobre a saúde de trabalhadores. I - Morbidade.
Rev. Saúde públ., S. Paulo, 22:311-26, 1988.

RESUMO: Realizou-se revisão bibliográfica crítica, com o propósito de estimar o impacto dos efeitos da ocupação sobre a morbidade de trabalhadores para, a partir de tal exercício, inferir as implicações sobre o setor saúde. As repercussões sobre a morbidade foram medidas através dos dados sobre acidentes do trabalho, intoxicaçðes agudas profissionais e doenças profissionais. Foram ainda incluídas outras "doenças relacionadas com o trabalho", exemplificadas com a hipertensão arterial, doenças respiratórias crônicas, doenças do aparelho locomotor, distúrbios mentais e estresse.
\end{abstract}

UNITERMOS: Doenças ocupacionais. Acidentes do trabalho. Saúde ocupacional. Riscos ocupacionais.

O presente estudo visa a facilitar o exercício de quantificação do impacto dos efeitos deletérios do trabalho sobre a saúde dos trabalhadores. Ainda que limitada na extensão, tal tentativa tem por propósito chamar a atenção para a importância do trabalho/ocupação como causa de doença e/ou de morte, e desta forma, para o necessário envolvimento do setor saúde que deve apreender o significado deste impacto e, de forma coerente, passar a ter um papel mais ativo nesta questão, visando interceptar, prevenir, controlar e erradicar as grandes causas de doença e morte de trabalhadores, relacionadas com o trabalho.

\section{ACIDENTES DO TRABALHO E INTOXICAÇÕES AGUDAS PROFISSIONAIS}

Dentre as várias formas de classificar os desvios da saúde relacionados com o trabalho, não há como escapar daquela que os agrupa em efeitos ou respostas a curto prazo, ou abruptos, ou "agudos", e em efeitos a médio e longo prazo, ou "crônicos". Entre os efeitos a curto prazo destacam-se os acidentes do trabalho (tipo) e as intoxicações agudas, de origem profissional.

A tentativa de quantificar os acidentes do trabalho em nosso meio passa necessariamente pela obrigação de citar as fontes oficiais, ainda que estes dados padeçam de uma série de limitações quantitativas e qualitativas, como tem sido largamente denunciado. Mesmo assim, serão apresentados os dados oficiais divulgados pelo
Instituto Nacional de Previdência Social (INPS) (Tabela 1), sem se deter excessivamente em sua análise, mesmo porque outros já o têm feito.

\section{TABELA 1}

Acidentes do trabalho ocorridos no Brasil, registrados pela Previdência Social, de 1968 a 1986.

\begin{tabular}{lccc}
\hline Ano & $\begin{array}{c}\text { Número de } \\
\text { trabalhadores } \\
\text { segurados }\end{array}$ & $\begin{array}{c}\text { Número de } \\
\text { acidentes } \\
\text { ocorridos }\end{array}$ & Incidência (\%) \\
\hline 1968 & 3.603 .489 & 454.097 & 12,60 \\
1969 & 7.268 .449 & 1.059 .296 & 14,57 \\
1970 & 7.284 .022 & 1.220 .111 & 16,75 \\
1971 & 7.553 .472 & 1.330 .523 & 17,61 \\
1972 & 8.148 .987 & 1.504 .723 & 18,47 \\
1973 & 10.956 .956 & 1.632 .696 & 14,90 \\
1974 & 11.537 .024 & 1.796 .761 & 15,57 \\
1975 & 12.996 .796 & 1.916 .187 & 14,74 \\
1976 & 14.945 .489 & 1.743 .825 & 11,67 \\
1977 & 16.589 .605 & 1.614 .750 & 9,73 \\
1978 & 18.500 .000 & 1.551 .501 & 8,39 \\
1979 & 20.322 .500 & 1.444 .627 & 7,11 \\
1980 & 23.782 .216 & 1.464 .211 & 6,16 \\
1981 & 24.448 .118 & 1.270 .465 & 5,20 \\
1982 & 20.668 .220 & 1.178 .472 & 5,70 \\
1983 & 22.562 .301 & 1.003 .115 & 4,45 \\
1984 & 25.065 .494 & 961.575 & 3,84 \\
1985 & 25.176 .791 & 1.075 .165 & 4,02 \\
1986 & - & 1.154 .480 & - \\
\hline
\end{tabular}

Fonte: Fundacentro - dados obtidos do INPS. Não divulgados.

* Centro Latino-Americano de Segurança, Higiene e Medicina do Trabalho (CLASET) da Organização Internacional do Trabalho (OIT) - Rua Capote Valente, 710 - 05409 - São Paulo, SP - Brasil. 
A Tabela 1 mostra que entre os trabalhadores cobertos pelo sistema urbano da Previdência Social (INPS), os acidentes do trabalho, cuja incidência vem aparentemente caindo a partir de 1973, ainda atingem mais de um milhão de trabalhadores por ano. Se for levado em conta o provável sub-registro e os significativos contingentes da população economicamente ativa não incluídos nesta estatística (por exemplo, os trabalhadores rurais, os do setor informal e/ou os que não contribuem para a Previdência), não é fora de propósito ter de triplicar estes números, para poder assim estimar a provável incidência de acidentes do trabalho no país. Isto elevaria à casa dos três milhões o número de acidentes por ano, com as suas óbvias repercussões médicas, sociais e econômicas, fartamente analisadas em outros estudos.

Parte destas repercussões podem ser exemplificadas através da Tabela 2 , onde aparecem os acidentes do trabalho administrativamente liquidados pelo INPS, segundo a conseqüência, de 1980 a 1985.

Chama a atenção, na Tabela 2, o número de trabalhadores que se incapacitam permanentemente e o número dos que morrem devido a acidente do trabalho.

A epidemiologia dos acidentes do trabalho em nosso meio, se por um lado é pobremente conhecida quando se analisam as estatísticas oficiais, por outro foi recentemente enriquecida através de vários estudos que serviram para elucidar importantes aspectos. Entre estes estudos, destacam-se o de Segre e Páscoa ${ }^{127}$, apresentado em 1974, e dedicado a analisar o problema dos acidentes do trabalho incapacitantes e mortais numa região pouco industrializada (Botucatu-SP); o de Mendes ${ }^{103,104}$ que analisa a epidemiologia de acidentes graves na capital de São Paulo, porém com interesse voltado à sua distribuição em relação ao tamanho da empresa; o de Nogueira e col. ${ }^{110}$, também dedicado ao estudo dos acidentes graves ocorridos na capital de São Paulo; o de Ferreira e Mendes ${ }^{47}$, que analisa a epidemiologia dos acidentes fatais ocorridos em Campinas-SP, a partir de registros no INPS; o de Olivan F. e col. ${ }^{113}$, que analisa os acidentes do trabalho fatais, na Grande São Paulo, no período de 1979 a 1982, a partir de laudos técnicos de acidentes encontrados no Instituto de Criminalística de São Paulo; o de Teixeira ${ }^{133}$ que analisa todos os acidentes do trabalho fatais, ocorridos em Santa Catarina, em 1981; os de Lopes ${ }^{42,93,94}$, voltados ao problema dos acidentes no trabalho rural, em Botucatu e em Lençóis Paulista, e a excelente contribuição de Vieira e col. ${ }^{141}$, que analisa detidamente a epidemiologia dos acidentes do trabalho rural no Estado do Paraná. Entre as mais interessantes contribuições nesta linha de trabalhos, situam-se os estudos de Faria e col. ${ }^{45,46}$ que serviram para elucidar aspectos poucos conhecidos da epidemiologia dos acidentes do trabalho. Todos estes estudos evidenciam com muita clareza o impacto que os acidentes causam na trajetória dos trabalhadores e o ônus social e econômico naturalmente associado.

As intoxicaçôes agudas de origem profissional são tipicamente exemplificadas pelas intoxicações por agrotóxicos, as quais têm sido objeto de inúmeros estudos em nosso meio 2,3,98, 107,130,135. Os programas de vigilância epidemiológica de agrotóxicos ou pesticidas, recentemente desenvolvidos em nosso país, revelam que o problema alcança dimensões seguramente alarmantes. O problema dos agrotóxicos extrapola os limites da saúde ocupacional, entrando no campo da saúde ambiental, porém com dimensões tais que o caracterizam como um verdadeiro problema de saúde pública*.

TABELA 2

Acidentes do trabalho liquidados, segundo a conseqüência, 1980 a 1985.

\begin{tabular}{lccrrr}
\hline \multirow{2}{*}{ Ano } & \multirow{2}{*}{ Total de acidentes } & \multirow{2}{*}{ Simples assistência médica } & \multicolumn{2}{c}{ Incapacidade } & \multirow{2}{*}{ Temporária } \\
& & & Permanente & Obitos \\
\hline 1980 & 1.505 .588 & 207.371 & 1.265 .468 & 27.925 & 4.824 \\
1981 & 1.309 .535 & 166.613 & 1.108 .193 & 29.921 & 4.808 \\
1982 & 1.218 .922 & 140.123 & 1.042 .487 & 31.816 & 4.496 \\
1983 & 1.050 .477 & 124.134 & 891.963 & 30.166 & 4.214 \\
1984 & 1.009 .516 & 131.174 & 845.206 & 28.628 & 4.508 \\
1985 & 1.088 .921 & 152.534 & 904.804 & 27.283 & 4.300 \\
\hline
\end{tabular}

Fonte: Fundacentro - dados obtidos do INPS. Não divulgados.

* São condições para que um problema de saúde seja considerado um "problema de Saúde Pública": a) seja causa comum de morbidade e mortalidade; $b$ ) que existam métodos eficazes de prevenção e controle; e c) que estes métodos não estejam sendo utilizados pela comunidade ${ }^{129}$. 


\section{DOENÇAS PROFISSIONAIS}

Por definição e segundo o conceito legal, as doenças profissionais ou tecnopatias não ocorrem na população geral. Somente esta característica já é suficiente para afirmar que a ocorrência destas doenças criadas pelas condições de trabalho ou pelos ambientes e/ou pelos processos de produção, por mais baixa que seja, é deplorável. Em outras palavras: são doenças totalmente evitáveis, como aliás vem sendo mostrado em países desenvolvidos $15,120,125,139,143$ e em estabelecimentos de trabalho que zelam pela integridade física e psíquica de seus empregados.

Em relação à ocorrência das doenças profissionais em nosso país, ocorre um fenômeno comum a outros países em mesmo estádio de desenvolvimento, ou seja, sua incidência, a julgar pelas estatísticas oficiais, é extremamente baixa. A Tabela 3 mostra a incidência das doenças profissionais no Brasil, de 1970 a 1986.

Verifica-se que a incidência de doenças profissionais está em torno de um a dois casos em 10 mil trabalhadores por ano, freqüência que, se fosse verdadeira, estaria entre as mais baixas no mundo, já que mesmo em países desenvolvidos a incidência anual de doenças profissionais está na faixa de 40 a 60 casos em cada 10 mil trabalhadores ${ }^{120,139,140 .}$

Contudo, não é difícil suspeitar que a verdadeira situação não é favorável assim. Devem estar ocorrendo tanto a falta de diagnóstico quanto o sub-registro dos casos diagnosticados,

\section{TABELA 3}

Doenças profissionais registradas no Brasil, 1970 a 1986

\begin{tabular}{lccc}
\hline Ano & $\begin{array}{c}\text { Empregados } \\
\text { segurados }\end{array}$ & $\begin{array}{c}\text { Doenças } \\
\text { profissionais }\end{array}$ & $\begin{array}{c}\text { Incidência } \\
\text { (por 1000) }\end{array}$ \\
\hline 1970 & 7.284 .022 & 5.937 & 0,815 \\
1971 & 7.764 .486 & 4.050 & 0,521 \\
1972 & 8.148 .987 & 2.475 & 0,304 \\
1973 & 10.956 .956 & 1.784 & 0,163 \\
1974 & 11.537 .024 & 1.839 & 0,159 \\
1975 & 12.996 .796 & 2.191 & 0,168 \\
1976 & 14.945 .489 & 2.598 & 0,174 \\
1977 & 16.589 .605 & 3.013 & 0,181 \\
1978 & 18.500 .000 & 5.016 & 0,271 \\
1979 & 20.322 .500 & 3.823 & 0,188 \\
1980 & 23.782 .216 & 3.713 & 0,156 \\
1981 & 24.448 .118 & 3.204 & 0,131 \\
1982 & 20.668 .220 & 2.766 & 0,133 \\
1983 & 22.562 .301 & 3.016 & 0,133 \\
1984 & 25.065 .494 & 3.283 & 0,131 \\
1985 & 25.176 .791 & 3.981 & 0,158 \\
1986 & - & 5.920 & - \\
\hline
\end{tabular}

Fonte: Fundacentro - dados obtidos do INPS. Não divulgados. a julgar por algumas evidências que, a titulo de exemplo, a seguir mencionaremos:

a) "O Inquérito Preliminar de Higiene Industrial no Município de São Paulo"'128, realizado pelo SESI em 1953-55, mostra, por exemplo, que $20,3 \%$ de todos os trabalhadores industriais do Município de São Paulo estavam expostos a agentes produtores de dermatoses ocupacionais; $7,3 \%$ de todos os trabalhadores estavam expostos a solventes orgânicos; $5,5 \%$, a poeiras de sílica; $5,4 \%$, a chumbo, e assim por diante (o Inquérito menciona cerca de 35 agentes ou grupos de agentes de doenças profissionais). Embora já tenham decorrido vários anos desde aquele Inquérito ${ }^{128}$, não existem indicadores que permitam afirmar que as condições de trabalho tenham rapidamente evoluído para melhor. Assim, emrbora não seja conhecida a proporção expostos/doentes, é lícito suspeitar que, apenas neste município, o número de casos de doenças profissionais supere em muito o número de casos registrados para o país todo, por ano.

b) Inquérito similar realizado no Estado do Rio de Janeiro, por Gondim e Latge ${ }^{67}$ mostra, por exemplo, que $25,6 \%$ de todos os trabalhadores industriais daquele Estado estavam expostos a poeiras orgânicas; $15,6 \%$, a temperaturas elevadas; $10,7 \%$, a poeiras silicosas; $10,5 \%$, a gases e vapores tóxicos, entre outros. Idêntico raciocínio permitiria inferir que a magnitude dos problemas das doenças profissionais no Rio de Janeiro deve assumir dimensões não imaginadas.

c) O exemplo do barulho - Através de um inquérito epidemiológico transversal realizado por Pereira ${ }^{116}$, foi mostrado que, a julgar pela prevalência encontrada pelo autor, devem existir atualmente cerca de 40.000 portadores de graus variados de surdez profissional, somente nas indústrias do Estado de são Paulo.

d) O exemplo das dermatoses profissionais Inquérito epidemiológico realizado no meio industrial de São Paulo por Belliboni e col. ${ }^{16}$, mostrou que em 2.138 trabalhadores examinados, 221 eram portadores de afecçס̃es cutâneas, das quais 73 foram consideradas de natureza ocupacional $(33 \%$ de todas as afecções $3,5 \%$ de todos os trabalhadores examinados). Se for levada em conta a "instantaneidade" do inquérito transversal, é lícito supor que a prevalência de $3,5 \%$ encontrada, no correr de um ano, eleva-se a uma incidência aproximada de $10 \%$. Assim, somente em relação às dermatoses profissionais, a incidência anual entre os trabalhadores industriais seria de 500 a 1.000 vezes superior 
àquela registrada no INPS, para as doenças profissionais como um todo.

e) O exemplo da silicose - Estudo epidemiológico realizado por Mendes ${ }^{101,102}$ permitiu estimar que, somente na região Sudeste do Brasil, existem atualmente de 20 a 30 mil portadores de silicose pulmonar nos seus diferentes estádios. Estudos mais recentes confirmam a gravidade do problema entre nós ${ }^{108,112}$

f) O exemplo do cromo - Gomes ${ }^{64,65}$, em seu clássico estudo realizado em trabalhadores de galvanoplastias sindicalizadas no Estado de São Paulo, mostrou a presença de perfuração do septo nasal em $24 \%$ dos trabalhadores examinados; $38,4 \%$ dos trabalhadores tinham ulceração de septo. Em conjunto, as lesões do septo nasal atingiam a mais de $50 \%$ dos trabalhadores. Por outro lado, mais da metade dos que lidavam com ácido crômico a quente apresentavam tosse e expectoração; mais de $60 \%$ tinham prurido nasal intenso; mais de $70 \%$ tinham espirros freqüentes quando expostos a névoas ácidas; mais de $60 \%$ apresentavam rinorréia e $30 \%$ tinham epistaxes freqüentes. O próprio autor faz estimativas da magnitude do problema em nosso país, a julgar pela elevada prevalência encontrada em seu estudo.

g) $O$ exemplo do asbesto - $\mathrm{O}$ asbesto constituise atualmente em um dos riscos ocupacionais/ambientais que maior preocupação vem trazendo aos países industrializados. Em nosso pais, após a contribuição importante de Nogueira e col.111, em 1975, apareceram novos estudos dedicados a estimar a magnitude dos problemas de saúde relacionados com a exposição ao asbesto ${ }^{38,39}$. Nesta linha de trabalhos destaca-se a contribuição de Costa ${ }^{37}$, que, a partir do levantamento de prontuários de sintomáticos respiratórios na Previdência Social no Município de Leme$\mathrm{SP}$, conseguiu detectar significativo número de casos de asbestose. Acredita-se que a utilização da mesma técnica em outras áreas onde existem em funcionamento indústrias que manipulam o amianto, mostraria a presença do mesmo problema, e em breve, também casos de câncer de pulmão e de mesotelioma de pleura e/ou de peritônio, como tem sido largamente observado nos países desenvolvidos.

Cotejando-se os dados oficiais - que, aliás, se ressentem da falta de dados qualitativos com os estudos clínicos e epidemiológicos que, de forma dispersa e fragmentada, mas irrefutável, mostram ângulos específicos do problema das doenças profissionais, torna-se forçoso re- conhecer a existência de uma notável carência de dados mais próximos à realidade, e que permitam uma visão de conjunto sobre a verdadeira magnitude desse problema em nosso país. Verifica-se, infelizmente, que, onde estas doenças começam a ser procuradas, graças a algum projeto específico de pesquisa ou, preferentemente, graças à implantação de programas de vigilância epidemiológica ${ }^{135} \mathrm{e} / \mathrm{ou}$ de atendimento de trabalhadores portadores de doenças profissionais 48.79 .87 , o problema dessas doenças surge e adquire dimensões não imaginadas, assumindo, em certos casos, características de verdadeiros "problemas de Saúde Pública", na acepção há pouco conferida ao termo.

Seria necessário esperar que se multipliquem os projetos de pesquisa com fins imediatos e as iniciativas isoladas de implantação de serviços ou ambulatórios de doenças profissionais, a fim de reforçar estas observações, para somente então entender que as doenças profissionais existem, e que são causa importante de morbidade, de incapacidades e até de morte? Já é tempo de o setor de saúde incorporá-las no elenco de suas preocupações e, coerentemente, assumir o seu papel, executando as ações que se requerem, e coordenando aquelas que outros podem e devem fazer, para interceptar, prevenir, controlar e, quiçá, erradicar estas doenças.

\section{DOENÇAS RELACIONADAS COM O TRABALHO}

Além da contribuição das doenças profissionais especificas, e sem dúvida ainda mais importante é a contribuição inespecífica do trabalho ou da ocupação à morbidade de trabalhadores. São as doenças em que o trabalho é fator contributivo (categoria II da classificação de Schilling ${ }^{125}$ ) e as doenças em que o trabalho é provocador ou agravador de distúrbios ou de doenças pré-existentes (categoria III da classificação de Schilling ${ }^{125}$ ) - mais flexivelmente, "doenças relacionadas com o trabalho", segundo o Comitê de Especialistas da OMS ${ }^{145}$. A seguir, serão mencionados alguns exemplos, na tentativa de apreender a "força" desta contribuição. O critério de escolha destes exemplos, leva em conta sua frequiência, ou seja, estão entre as causas mais comuns de morbidade, e alguns constituem também causa importante de incapacidade.

\section{Hipertensão Arterial}

A hipertensão arterial constitui um problema de saúde da mais significativa relevância, já que afeta $10 \%$ ou mais da população adulta. Essa alta prevalência acarreta graus variáveis de in- 
capacidades e uma diminuição na expectativa de.vida do hipertenso, principalmente devido à insuficiência cardíaca e/ou à insuficiência vascular cerebral, coronariana e renal ${ }^{89,144,146 .}$

Entre os fatores de risco da hipertensão arterial, são tidos como relativamente bem conhecidos a obesidade, a ingestão excessiva de sal, a inatividade física, o tabagismo, a ingestão de álcool, e um grupo um tanto impreciso de " $f a$ tores psicologicos"', incluindo o estresse ${ }^{144,146}$. Por outro lado, alguns trabalhos fazem menção à possível influência do barulho excessivo, de vibrações localizadas e de corpo inteiro, assim como de exposição ao calor excessivo $0^{10,11,63,84}$. Esses estudos ainda se ressentem da falta de uma fundamentação científica mais sólida, e não é por este caminho que a contribuição do fator ocupação tem sido enfocada, no problema da hipertensão ${ }^{109}$.

A possivel contribuição da ocupação como fator de risco na hipertensão tem sido entendida como associada aos "fatores psicológicos" ou "fatores psicossociais" geradores de estresse $^{109}$. Em situações de estresse "agudo" aumentam os niveis de adrenalina, de noradrenalina e de cortisol. Contudo, não está suficientemente comprovado que a repetição continuada de situações de estresse "agudo" acompanhadas de elevação transitória da pressão arterial, por si só provoca a elevação permanente da pressão ${ }^{144,145,146}$.

Alguns estudos epidemiológicos, contudo, levam a sugerir que isto efetivamente ocorre. Assim, por exemplo, Kasl e Cobb ${ }^{77}$ descreveram a associação entre hipertensão arterial e perda do emprego. Cobb e Rose ${ }^{32}$ citaram elevada prevalência de hipertensão em controladores de tráfego aéreo, quando comparados com seus próprios exames admissionais e com um grupo controle de colegas em outras atividades de mais baixo nível de exigência psíquica. Aliás, mostraram também que a prevalência da hipertensão arterial entre controladores de tráfego aéreo em torres de grande movimento era 1,6 vezes a prevalência de seus colegas em torres de pequeno movimento.

A provável influência de fatores estressores ocupacionais na produção da hipertensão arterial vem sendo detectada no Brasil, e alguns estudos podem ser mencionados como exemplo deste tipo de preocupação. Assim, Ribeiro e col. ${ }^{119}$, da Escola Paulista de Medicina, estudaram os níveis pressóricos de 5.500 trabalhadores no Município de São Paulo, distribuídos em 57 diferentes estabelecimentos de trabalho. Além da influência da idade, do sexo e do grupo racial, estes autores encontraram significativa diferença na prevalência da hipertensão, quando os trabalhadores foram agrupados segundo o ramo de atividade econômica. Assim, os ramos econômicos onde a prevalência da hipertensão foi mais elevada em seus trabalhadores foram: a indústria metalúrgica $(17,3 \%$ de prevalência), o setor bancário e securitário $(18,6 \%)$, o setor de transportes públicos $(18,9 \%)$ e de empresas jornalísticas e publicitárias $(21,0 \%)$; os níveis mais baixos foram encontrados em empregados da indústria automobilística $(11,4 \%)$, no comércio $(12,1 \%)$, em trabalhadores têxteis $(12,9 \%)$ e entre profissionais liberais $(11,0 \%)$. Foi detectada pelos autores ${ }^{119}$ uma tendência de existirem níveis pressóricos mais elevados em trabalhadores que excediam a média de 48 horas de trabalho/semana, quando comparados com os que trabalhavam menos que aquele limite. Acreditam aqueles autores que essas diferenças podem ser associadas a fatores ocupacionais, ligados à organização do trabalho, ao ritmo e duração do trabalho e ao estresse inerente a algumas destas ocupações.

Outros pesquisadores em nosso meio têm tentado analisar o problema da hipertensão arterial a partir de sua distribuição na comunidade, porém em grupos sócio-ocupacionais mais amplos, tendendo a agrupá-los segundo classe social. Araújo ${ }^{13}$, por exemplo, ao analisar o problema da hipertensão arterial em Volta Redonda-RJ, chegou à conclusão que a prevalência é da ordem de $10,1 \%$, porém "a distribuição não é igualitária, os maiores danos ocorrendo nos grupos de ocupaçoes dos estratos sociais inferiores". Aquele autor observou que entre os profissionais técnico-científicos e administradores, a prevalência foi de $2,9 \%$, enquanto que em trabalhadores de prestação de serviços foi $16,0 \%$. No intervalo entre os extremos, observou prevalência de $6,2 \%$ entre "pequenos burocratas" e comerciários, $9,4 \%$ entre pessoas que nunca trabalharam e 11,1\% em trabalhadores da indústria de transformação. Baseado nesses dados, o autor conclui que "fatores que permeiam os estratos sociais estão fortemente associados à gênese da hipertensão arterial em Volta Redonda, e a associação dá-se no sentido inverso do gradiente de classe social"' (sic).

Klein $^{82}$, por sua vez, ao estudar a hipertensão arterial em estratos geoeconômicos do Rio Grande do Sul, observou importantes diferenças entre os quatro estratos analisados, ou seja, $9,25 \%$ em adultos do "interior rural", $11,45 \%$ em adultos do "interior urbano", 12,32\% na cidade de Porto Alegre, e $13,76 \%$ no que chamou de "cinturão metropolitano". Aqui também o autor concluiu que a hipertensão parece ser fortemente influenciada pelo setor de atividade econômica e pela posição social, definida 
pela relação de trabalho e grau de educação dos individuos, retirados os efeitos de idade e sexo. As taxas mais baixas de hipertensão arterial são as dos individuos das camadas superiores do setor secundário e terciário, de donos de empresas e profissionais de nível superior, enquanto que as mais elevadas ocorrem nas camadas sociais inferiores dos mesmos setores, de assalariados, autônomos, auxiliares e biscateiros de médio ou baixo grau de educação.

Carvalho ${ }^{29}$ estudou a prevalência da hipertensão arterial em 1773 individuos do sexo masculino, de 20 a 70 anos, pertencentes a sete grupos sociais e profissionais: 200 médicos, 167 trabalhadores rurais, 151 índios, 218 operários de indústria, 205 presidiários, 669 praças e 163 oficiais da Marinha. A maior taxa de hipertensão foi observada em presidiários $(26,3 \%)$ e a menor em oficiais. Concluiu o autor que "os grupos pertencentes a escalas sociais economicamente desfavorecidas e os submetidos a elevado nível de repressão evidenciaram maior prevalência de hipertensão arterial"'.

Para completar a apresentação dos estudos brasileiros que seguem esta linha de trabalho, devem ser mencionados a tese de Costa ${ }^{34}$, o relatório de pesquisa apresentado por Costa e Klein ${ }^{35}$, e os trabalhos mais recentes de Costa e Klein ${ }^{36}$ e o de Klein e Araújo ${ }^{83}$.

Esses estudos, e outros inumeráveis publicados na literatura estrangeira, permitem que sejam delineadas algumas conclusôes relativas à influência do trabalho ou ocupação na determinação da hipertensão arterial, a saber:

- os estudos epidemiológicos transversais ou de prevalência são unânimes em demonstrar um excesso de risco ou um risco atribuivel ao trabalho em determinadas ocupações, o qual pode ser estimado através da diferença entre prevalência normal na população adulta, e a encontrada em algumas ocupações ou em alguns ramos de atividade, após correção para mesma idade e sexo;

- o excesso de risco atribuível à ocupação parece ser devido mais a fatores estressores decorrentes da organização do trabalho, incluindo o ritmo, a duração da jornada, o trabalho em turnos, a sobrecarga psíquica, que propriamente à presença de agentes físicos ou químicos (ainda que sejam conhecidos agentes que a longo prazo podem produzir hipertensão, como é o caso do chumbo, por exemplo);

- a complexidade das inter-relações entre ocupação e hipertensão ultrapassa o limite da saúde ocupacional, estrito senso, passa pela saúde ambiental um tanto mais ampla, até adquirir uma dimensão social, ou até política e ideológica, como propõem Schnall e Kern ${ }^{126}$ e alguns outros;

- qualquer que seja a forma de entender o problema, a hipertensão arterial constitui exemplo típico de doença relacionada com o trabalho que tem de ser abordada pelo setor saúde de forma integral e integrada. Seu papel não pode permanecer limitado ao tratamento dos hipertensos e ao pagamento da incapacidade provocada pela hipertensão.

\section{Doenças Respiratórias Crônicas}

Além das pneumoconioses, cujo nexo causal com a exposição a poeiras de origem ocupacional está definitivamente estabelecido, algumas doenças respiratórias crônicas não específicas - notadamente a bronquite crônica, o enfisema pulmonar e asma brônquica - já de há muito têm sido consideradas como relacionadas com o trabalho. Sua incidência e prevalência em determinadas ocupações são inequivocamente superiores àquelas na população geral de adultos, ou em outras ocupações. A evidência é fundamentalmente epidemiológica, e está baseada em estudos transversais que comparam a prevalência de sintomas ou achados funcionais em grupos expostos com grupos não expostos, tomados como testemunhas.

A razão de escolher as doenças respiratórias crônicas como exemplo da influência inespecífica do trabalho sobre a saúde prende-se a três aspectos importantes. O primeiro, relaciona-se à extraordinária importância das doenças respiratórias crônicas como causa de morbidade, de incapacidade, de absentismo e de mortalidade, como é sobejamente conhecido pelos que trabalham em saúde pública ${ }^{88}$. O segundo aspecto, tal como no caso da hipertensão arterial, é porque se trata de um grupo de doenças onde os fatores etiológicos e agravadores se interpenetram com tamanha complexidade que se torna quase impossível desentranhá-los para isolar a contribuição estritamente ocupacional. O terceiro, na verdade uma decorrência do segundo, diz respeito à invasăo que freqüentemente ocorre em relação aos agentes etiológicos destas doenças que, ignorando muros ou cercas, atingem a comunidade geral, caracterizando a assim chamada poluição ambiental.

Com tal pano de fundo, tomaremos deste grupo de doenças apenas o exemplo da bron. quite crônica, conscientes da controvérsia que existe sobre a existência ou não, da bronquite ocupacional, ou bronquite industrial ${ }^{105,106,145}$. (Entre nós, o assunto já foi tema de tese de Livre-Docência, elaborada por Campos ${ }^{26}$, em 1966). A bronquite crônica tem sido definida 
como "uma síndrome crônica caracterizada por tosse com expectoração mucosa ou mucopurulenta, com duração de pelo menos três meses durante dois anos consecutivos, não resultando de outra causa aparente, como tuberculose, bronquiectasia e outras" $4,31,99$.

A bronquite crônica não depende de um fator etiológico único e determinado, mas da soma de vários fatores, entre os quais se destacam o fumo, a poluição atmosférica, as infecções e a ocupação. A bronquite crônica simples manifesta-se pela persistência de tosse com expectoração, na ausência de doenças respiratórias específicas. A bronquite crônica obstruti$v a$, freqüentemente incluída no termo genérico de doença pulmonar obstrutiva crônica (DPOC) (que abrange o enfisema pulmonar e a bronquite), é definida pela presença adicional de obstrução das vias aéreas, traduzida clinicamente pela dispnéia, e funcionalmente pela redução da razão entre o Volume Expiratório Forçado no 1 : segundo $\left(\mathrm{VEF}_{\text {, }}\right.$ ) e a Capacidade Vital Forçada (CVF). Em contraste com a mera presença de tosse e expectoração, a presença de obstrução pode ter importante impacto sobre a morbidade e a mortalidade ${ }^{105,106,138}$.

Isto posto, mencionaremos alguns exemplos da magnitude da influência da ocupação na "história natural" da bronquite crônica, lembrando que vapores, gases, fumos e poeiras, originados nos ambientes e nos processos de trabalho, podem exercer importante efeito contributivo.

Assim, já se tornaram clássicos os estudos em mineiros do carvão, que mostraram a produção de bronquite crônica independente ou concomitantemente com a pneumoconiose dos trabalhadores do carvão ${ }^{106}$. Em estudos realizados em comunidades de mineiros do carvão e de exmineiros, foi encontrado aumento da prevalência de bronquite crônica, de 1,2 a 6,4 vezes, em relação aos não-mineiros ${ }^{68,69}$.

Por outro lado, em estudos transversais realizados em 847 trabalhadores da indústria de cimento, comparados com os realizados em 460 trabalhadores não expostos a riscos ocupacionais, foi observado que $19,0 \%$ dos expostos ao cimento tinham bronquite crônica simples, enquanto que entre os controles, a prevalência foi de apenas $9,62 \%$. Outrossim, entre os trabalhadores da indústria do cimento, não fumantes, a prevalência encontrada foi de $11,7 \%$, enquanto que entre os controles, também não-fumantes, foi de apenas 2,2\%. Entre os expostos fumantes, $21,2 \%$ tinham bronquite crônica simples, enquanto os expostos não-fumantes mostraram uma prevalência equivalente à metade daquela encontrada em seus colegas fumantes. Estes achados mostram de forma inequivoca o excesso de risco atribuível à ocupaçăo, bem como o efeito aditivo entre a poeira de cimento e o fumo ${ }^{74,75,76}$.

Dosman e col44, no Canadá, investigaram as queixas respiratórias em trabalhadores que lidam com silagem de grãos, tomando para tanto 90 trabalhadores que nunca haviam fumado, e compararam seus sintomas respiratórios com os de 90 trabalhadores considerados não expostos, igualmente não fumantes, e devidamente emparelhados por idade. Verificaram aqueles autores que $23,1 \%$ dos trabalhadores daquele ramo tinham tosse e expectoração, enquanto que entre os controles a prevalência foi de apenas 3,3\% - diferença que dá idéia de um risco relativo de oito vezes, e de um risco atribuivel de $19,8 \%$, ou seja, $86 \%$ do risco de bronquite crônica simples corre por conta da natureza da ocupação (garantida a eliminação de variáveis de confundimento). Outrossim, quando os trabalhadores foram agrupados segundo o tempo no emprego, os autores verificaram que a prevalência de bronquite crônica simples entre os que tinham menos de cinco anos foi de $14,3 \%$, enquanto que entre os que tinham mais de 20 anos de trabalho, a prevalência foi de $35,7 \%$. Este achado reforça a idéia de causalidade entre a exposição a poeiras de cereais e a produção de bronquite crônica.

Estudos realizados com soldadores mostram também os efeitos de gases irritantes (dióxido de nitrogênio, ozone, fosgênio e outros) de fumos metálicos (cádmio, zinco, ferro e outros) e de poeiras, sobre o trato respiratório desses trabalhadores. Por exemplo, Antti-Poika e col. ${ }^{12}$, do Instituto de Saúde Ocupacional de Helsinque, na Finlândia, investigaram sintomas respiratórias em 157 soldadores a arco, sem sinais radiológicos de siderose, e em 108 trabalhadores de oficinas mecânicas, tomados como controles, emparelhados segunido idade, hábito de fumar e classe social. Sintomas que caracterizaram bronquite crônica simples foram encontrados em $24 \%$ dos soldadores, enquanto que entre os controles a prevalência foi de $14 \%$.

Oxhoj e col. ${ }^{114}$ investigaram a sintomatologia respiratória de 119 soldadores a arco, comparando-a com a de 90 trabalhadores em outras funções. A prevalência entre soldadores e seus controles (ambos os grupos nãofumantes) foi de $31 \%$ e $11 \%$, respectivamente. A comparação entre soldadores fumantes e controles fumantes foi de $77 \%$ para os primeiros, contra $43 \%$ para os últimos.

Em nosso meio, Gomes ${ }^{66}$ estudou a saúde de trabalhadores soldadores, porém os instrumentos utilizados em sua investigação não lhe per- 
mitiram detectar o problema da bronquite crônica na população estudada.

Buscando detectar os efeitos da exposição ao dióxido de enxofre, Archer e Gillam ${ }^{14}$ compararam 953 trabalhadores de uma fundição de cobre com 252 controles tomados de uma oficina de manutenção da mesma empresa, e analisaram a sintomatologia respiratória. A prevalência de bronquite crônica simples entre expostos - fumantes e não-fumantes - foi $15,8 \%$, enquanto entre os controles foi $9,5 \%$.

Por outro lado, Fine e Peters ${ }^{49}$, ao investigarem a presença de queixas respiratórias em trabalhadores da cura de borracha, encontraram em $25,8 \%$ dos empregados desse setor a referência a tosse crônica com produção de escarro; entre os controles a prevalência foi de $14,3 \%$.

Por último, uma curta menção a trabalhadores de coqueria, expostos a emissōes de fornos de coque. Quando 312 trabalhadores diretamente expostos às emissões foram comparados com 464 colegas da mesma área, porém não diretamente expostos às emissões, verificou-se que existia entre os fumantes uma diferença de $32 \%$ para $23 \%$ quanto à prevalência de bronquite crônica simples. Entre não-fumantes, esta diferença foi de $9 \%$ para $6 \%$. Estes dados servem para mostrar, além do excesso de risco atribuivel à exposição às emissões dos fornos de coque, um provável efeito potencializador entre este risco e o provocado pelo fumo ${ }^{142}$.

\section{Doenças do Aparelho Locomotor}

As afecçðes do aparelho locomotor (ou sistema músculo-esquelético-ligamentar) constituem importante causa de morbidade e de incapacidade de adultos, e sua importância médicosocial e econômica tem chamado a atenção de planejadores e administradores de saúde e de seguridade social, no mundo inteiro $0^{5,20,40,81,123,145}$. Este grupo de afecções é aqui mencionado, tanto por sua notória importância em termos de saúde pública, como também para exemplificar o extraordinário impacto que a ocupação (ou o trabalho) exerce sobre a história natural destas afecções. A compreensão de tal contribuição servirá para mostrar, mais uma vez, a complexa interpenetração de fatores causais ditos ocupacionais. Servirá, para chamar a atenção das autoridades sanitárias para o pesado impacto econômico e de demanda a serviços de saúde, que a ocupação, direta ou indiretamente, acarreta enquanto determinante de morbidade da população. Por último, este grupo de afecções prestase bem para exemplificar doenças relacionadas com o trabalho, passíveis de controle, através, principalmente, das contribuições da ergonomia, da organização racional do trabalho e da educação para a saúde.

Neste grupo de afecções estão incluídas as dores de coluna (dor lombar, lombalgias, dores nas costas, e outros), as osteoartroses, as cérvico-branquialgias ${ }^{7}$, as tenossinovites e peritendinites ${ }^{86,124}$ entre outras; apesar de sua importância, não serão incluídos os traumatismos agudos que resultam em fraturas, luxaçōes, amputaçס̃es, perda de substância, entre outras, mencionados implicitamente sob a rubrica dos acidentes do trabalho. Servirá de paradigma das doenças do aparelho locomotor, a dor lombar.

A importância da dor lombar pode ser medida através de diferentes indicadores, que incluem: sua incidência e prevalência na população geral de adultos e em comunidades de trabalhadores; a magnitude da sua participação nas causas de absentismo ao trabalho, de incapacidade temporária ou permanente, e mesmo de invalidez; o custo econômico sobre os sistemas de seguridade social; a posição relativa entre as doenças profissionais (nos países em que elas podem ser assim caracterizadas), além de outros. Todos estes indicadores, isoladamente ou de forma combinada, põem em destaque a extraordinária importância da dor lombar, sob qualquer ângulo que $\circ$ problema for analisado $1,8,9,17,62,121,122,137,147,148$.

Assim, em termos de prevalência, Magora ${ }^{95,96,97}$, em Israel, detectou a presença de dor lombar em $12,9 \%$ de todos os trabalhadores investigados, pertencentes a oito diferentes ramos de atividade. Brown ${ }^{22}$, através de questionário enviado a trabalhadores da indústria de transformação, observou que $35 \%$ dos homens e $46 \%$ das mulheres faziam referência a dores na coluna lombar. Rowe ${ }^{121}$, através de um estudo retrospectivo sobre os motivos que levaram trabalhadores a procurar atendimento médico no período dos últimos dez anos, observou que a dor lombar foi mencionada por $47 \%$ dos empregados em trabalhos pesados e por $35 \%$ dos que exerciam atividades sedentárias. Gibson e col. ${ }^{62}$, ao acompanharem durante $12 \mathrm{me}$ ses uma coorte de trabalhadores de indústria siderúrgica, observaram queixas de dor lombar em $60 \%$ dos trabalhadores. Anderson ${ }^{5}$, no Reino Unido. cita uma investigação sobre problemas músculo-esqueléticos, realizada em 2.648 trabalhadores, sorteados a partir de uma grande variedade de ocupações. Foi observado que mais da metade dos trabalhadores $(52 \%)$ afirmaram ter tido problemas reumáticos durante sua vida laboral; destes, 805 , ou seja, $30 \%$ dos trabalhadores estudados fizeram referência a 


\section{dores nas costas durante o tempo em que traba-} lharam.

Quanto a dados de prevalência no Brasil, são conhecidas as estimativas feitas por reumatologistas como Samara ${ }^{123}$ e Bonomo ${ }^{20}$, segundo os quais existem de oito a dez milhões de pacientes reumáticos, senso lato.

A importância da dor lombar pode também ser ilustrada quando é analisada sua contribuição como causa de incapacidade e/ou invalidez para o trabalho ${ }^{87,147}$, e como causa de absentismo ${ }^{122}$.

Buscando conhecer melhor a importância das doenças de coluna em nosso país, Knoplich ${ }^{85}$ utilizou os dados de perícias médicas do INPS, que normalmente traduzem a importância das doenças que provocam incapacidade temporária ou permanente para o trabalho. Assim, em 1976, as doenças reumáticas - principalmente as doenças da coluna - ocupavam o terceiro lugar entre as doenças incapacitantes, superadas somente pelas neuroses e pela hipertensão arterial. Já nos dados relativos a 1978, essas doenças passaram para o segundo lugar (superadas apenas pelas neuroses).

A Tabela 4, extraída do trabalho de Medina ${ }^{100}$, resume a importância relativa das principais doenças incapacitantes, registradas pela perícia médica do INPS.

Face à não uniformidade de terminologia utilizada por reumatologistas e ortopedistas, e devido a mudanças nos critérios de classificação utilizados pelo INPS, Knoplich ${ }^{85}$, reordenou diferentes grupos de doenças, na tentativa de melhorar a estimativa do significado das doenças de coluna. Após este tratamento, o autor chegou à conclusão de que a prevalência da osteoartrose de coluna pode ser estimada em 3,8 casos por mil segurados. Segundo Knoplich ${ }^{85}$, "de cada 100 segurados com incapacidade temporária, mantidos no Auxílio-Doença do INPS,

\section{TABELA 4}

Principais causas de aposentadoria por invalidez - Brasil, 1983

\begin{tabular}{lrr}
\hline Causa invalidante & N. & $\%$ \\
\hline Hipertensão arterial & 29.399 & 20,0 \\
Transtorno mental & 21.506 & 14,7 \\
Doenças ósteo-articulares & 17.304 & 11,8 \\
Doenças cardio-vasculares & 15.463 & 10,6 \\
Epilepsia & 5.410 & 3,7 \\
Doenças infecto-contagiosas & 4.944 & 3,4 \\
Demais & 52.376 & 35,8 \\
\hline Total & 146.402 & 100,0 \\
\hline
\end{tabular}

Extraído de Medina ${ }^{100}$ (1986). em $1978,4,83$ casos são devidos a doenças reumáticas e, dentre estes, 3,8 apresentam problemas de coluna, perfazendo, portanto, $82 \%$ de todos os pacientes com problemas crônicos de sistema osteo-músculo-ligamentar" 8 .

Entre nós, a importância do problema tem sido confirmada através de outros estudos, quer analisando a experiência de determinada empresa ${ }^{28,115}$, quer de determinado setor da economia ${ }^{54,55}$, quer como casuística de processos judiciais que chegaram às Varas de Acidentes do Trabalho $50,51,70$.

A questão da dor lombar apresenta facetas extremamente interessantes, que enriquecem esta discussão sobre o impacto da ocupação sobre a morbidade de trabalhadores, e as implicaçðes para o Setor Saúde. Excluídas causas específicas de dor lombar (causas inflamatórias, degenerativas, neoplásicas, e outras), e levados em consideração fatores de risco (defeitos congênitos, fraqueza da musculatura, predisposição reumática e sinais de degeneração da coluna ou dos discos intervertebrais), a causa mais comum é não-específica, de patologia indeterminada, e frequientemente associada a problemas ergonômicos ou traumáticos ${ }^{145}$.

Efetivamente, a dor lombar aparece com freqüência mais elevada em trabalhadores que exercem atividades pesadas, de ritmo intensivo, e em condições antiergonômicas, tais como estivadores, trabalhadores de transportes e cargas, mineiros em trabalhos subterrâneos, serventes de pedreiro na construção civil, além de trabalhadores expostos a vibrações de corpo inteiro, como é o caso de motoristas de caminhão, tratoristas e operadores de veículos pesa-

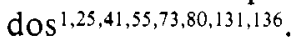

Numerosos estudos chamam a atenção para a importância do esforço de flexão, principalmente pela posição incorreta de erguimento de pesos, em geral associado ao trabalho pesado $18,22,23,24,28,30,58,73,96,97,115$. Estes fatores agravadores ou precipitantes têm sido identificados na imensa maioria dos casos, ainda que dificilmente possa ser evidenciada a lesão que corresponde ao trauma agudo desencadeador do quadro. Desta forma, a evidência inequívoca de nexo entre dor lombar e atividade ocupacional é a freqüência significativamente elevada nas atividades que exigem grande esforço físico, em ritmo ou intensidade excessivos e em condições claramente não ergonômicas. A evidência é fundamentalmente epidemiológica, isto é, detecta-se um excesso de risco atribuível à ocupação, como aliás ficou mostrado há pouco, quando as diversas taxas de prevalência foram mencionadas. 
Em geral, 80\% dos casos de dor lombar melhoram com o repouso e tratamento em duas a três semanas, embora 10 a $15 \%$ dos casos possam requerer tratamento que dure um ano, ou mais ${ }^{145}$. Knoplich ${ }^{85}$ menciona que, de acordo com os dados dos relatórios da Perícia Médica do INPS, as doenças reumáticas necessitam em média de 240 dias, ou seja, oito meses para uma recuperação. Resulta daí uma perda anual de mais de 25 milhões de dias de serviço para serem pagos pela Previdência Social, referindo-se aos dados de 1975.

\section{Distúrbios Mentais e Estresse}

Os desvios da saúde mental, em graus variados de complexidade e duração, contribuem significativamente no peso da morbidade da população geral, a julgar pelos indicadores de prevalência em inquéritos de morbidade, pelo número de atendimentos médicos e de internações hospitalares e pela importância das doenças mentais como causa de incapacidade para o trabalho.

Assim, estima-se que nas áreas metropolitanas brasileiras, à semelhança do que ocorre em outros países, cerca de $18 \%$ da população necessita de algum tipo de ajuda psiquiátrica, e para estes, estima-se a necessidade de duas consultas médicas por ano, o que por si só demonstra a repercussão desses problemas sobre a infra-estrutura de serviços de saúde ${ }^{132}$.

Por outro lado, tem sido estimado que 5 a $10 \%$ da força-de-trabalho ocupada sofre de problemas de saúde mental considerados sérios, e que cerca de $30 \%$ sofre de algum tipo de desconforto psíquico, de menor proporção 21,145 Como já foi mencionado a propósito das causas de incapacidade temporária e de incapacidade permanente entre segurados da Previdência Social no Brasil, as assim rotuladas "psiconeuroses" ocupam o primeiro lugar entre as causas de incapacidade temporária, e o segundo e o terceiro lugar entre as causas de incapacidade permanente e invalidez ${ }^{85,118}$. Saliente-se que o tempo médio de afastamento do trabalho concedido pelo INPS para as psiconeuroses é de dez meses ${ }^{132}$.

É bem provável que estas estatísticas, impressionantes como são, venham carregadas de grandes imprecisões, umas decorrentes de critérios de classificação dos desvios da saúde mental, outras decorrentes da diversidade de instrumentos para medí-los. Assim, a "família" dos distúrbios mentais pode estar englobando desde as psicoses (esquizofrenia, psicose maníacodepressiva, psicose senil, psicose orgânica e outras), passando pelos distúrbios psiconeuróticos (estados de ansiedade, de depressão, de histeria e outros), até o estresse. Naturalmente são problemas que recebem enfoques terapêticos e administrativos muito diferentes e que não podem ser postos, indiscriminadamente, sob um mesmo denominador. Por outro lado, existe grande diversidade quanto às fontes de informação, que vão desde inquéritos baseados em entrevistas domiciliárias até dados de atendimento em ambulatórios e consultórios especializados, de internação em hospitais psiquiátricos e de casuísticas de Serviços Médicos de Empresa, que às vezes incluem dados de absentismo. Como é largamente conhecido, entram em cena não apenas aspectos médicos, porém, muito especialmente, aspectos administrativos, políticos e ideológicos, como aliás muito bem salienta Timio ${ }^{134}$, a propósito das internações psiquiátricas na União Soviética.

Qual a influência do trabalho ou da ocupação sobre a morbidade devida aos distúrbios mentais e ao estresse? Naturalmente, difícil será responder com precisão, já que esta resposta estará baseada sobre o ponto de confluência de dois territórios de difícil delimitação: o do conceito e extensão de trabalho, e o de conceito e extensão de distúrbios mentais, como foi comentado. Contudo, alguns aspectos já têm sido esclarecidos, e serão sucintamente mencionados com o propósito de salientar, mais uma vez, a "força" da ocupação (ou do trabalho) na morbidade e a respectiva repercussão sobre o setor saúde, particularmente os serviços de saúde.

Assim, num primeiro nível, podem ser mencionadas as intoxicações profissionais cuja ação sobre o sistema nervoso central, particularmente sobre as funções psíquicas, já tem sido fartamente descrita a nível experimental e clínicoepidemiológico. Exemplificam este grupo, o chumbo (encefalite e suas sequielas), o monóxido de carbono (seqüelas pós-intoxicação aguda), o sulfeto de carborio, os pesticidas organofosforados e organoclorados, o mercúrio, os efeitos agudos causados pela inalação de solventes clorados e aromáticos, o estireno, além das seqüelas de traumatismos crânioencefálicos ${ }^{52,53,117}$. Nos últimos anos, vem recebendo crescente atenção o campo da toxicologia comportamental, quer pelo número de substâncias químicas que agem sobre o comportamento de trabalhadores expostos, quer pela sensibilidade introduzida nos métodos semiológicos, e a conseqüente importância que vem sendo atribuída a alterações discretas, que não eram suficientemente valorizadas pela saúde ocupacional nos paises do ocidente ${ }^{19,59,72}$.

Num segundo nível, a relação trabalhodistúrbio mental faz-se indiretamente. Existin- 
do fatores predisponentes que fazem com que umas pessoas sejam mais vulneráveis a distúrbios emocionais do que outras (personalidade, estado geral de saúde, qualidade geral de vida*, e outros), o trabalho ou a ocupação podem contribuir como fatores precipitadores. Estes são eventos ou experiências que rompem o equilíbrio emocional e têm um relacionamento temporal muito próximo ao distúrbio, quando de sua manifestação. Poderão coexistir outros fatores precipitadores, tais como doenças pessoais, problemas familiares, problemas financeiros, entre outros. Os distúrbios de personalidade e os sintomas neuróticos que mais comumente se manifestam são a ansiedade, a depressão e a reação histérica.

Num terceiro nível situa-se o intrincado problema do estresse e sua relação com o trabalho. O estresse - "algo que ocorre quando um indivíduo se comporta em situações para as quais sua maneira habitual de enfrentar torna-se insuficiente" 78 — tem sido abordado sob diferentes perspectivas.

Um dos enfoques predominantes é o do " "ajustamento pessoa-meio-ambiente", ("person-environment fit"), segundo o qual o estresse seria um "desbalanço" entre a demanda e a capacidade de resposta, em condições tais que a falha para atender a demanda tem importantes conseqüências. Sob este enfoque, $e$ num nivel mais limitado de compreensão, o estresse traduz situaçôes em que a demanda supera a capacidade de resposta, e em relação ao trabalho, explicitaria situações de sobrecarga ou de superestimulação. Numa visão mais abrangente, o ajustamento inadequado entre pessoa e meio-ambiente envolveria não apenas variáveis quantitativas, do tipo demanda vs. capacidade de resposta, mas também necessidades pessoais, emocionais e fontes de satisfação no trabalho. Assim, o estresse poderia originarse, igualmente, de situações opostas às anteriores, ou seja, de situações de subutilização, de carga inferior às possibilidades (underload) $27,33,60,61,71$.

Levi $^{90,}$ 91, um dos pesquisadores suecos que mais se destacam nos estudos sobre estresse e seus fatores psicossociais, identifica como "principais estressores psicossociais no trabalho", os seguintes:
- sobrecarga quantitativa: muita coisa para fazer, em pouco tempo;

- carga qualitativa inferior às possibilidades (underload): atividades pouco estimulantes ou desafiadoras, que não exigem criatividade, monótonas e repetitivas;

- conflitos de papéis e responsabilidades: "no trabalho, somos filhos, pais, cônjuges, amigos, membros de clubes, entidades, sindicatos, e nem sempre podemos cumprir bem estes diferentes papéis, simultaneamente" ${ }^{90}$;

- falta de controle sobre a sua própria situação: outros decidem pelo trabalhador o que fazer, onde, e como, inclusive ritmos e velocidades;

- falta de apoio social: chefias, colegas de trabalho e outros;

- estressores físicos: barulho, calor ou frio extremos, iluminação deficiente ou excessiva, odores incômodos e outros;

- estressores específicos da indústria: tecnologia de produção em massa, processos de trabalho altamente automatizados, e trabalho em turnos**90,91

Levi $^{90}$ discute os tipos de reações que ocorrem em decorrência ao estresse, agrupando-as em a) reaçōes emocionais: ansiedade, depressão, histeria e outros; b) reações comportamentais: alcoolismo, tabagismo excessivo, dependência de drogas, aumento do absentismo e, em casos extremos, o suicídio; c) reações fisiológicas: alterações hormonais e farmacológicas que provocam taquicardia, sudorese, hipertensão arterial, aumento de lipidios sangüíneos, além de outras.

Os três niveis aqui tomados para exemplificar a influência do trabalho sobre a morbidade devida aos distúrbios e às doenças mentais - as intoxicações profissionais, os distúrbios psiconeuróticos precipitados pelo trabalho, o estresse - tipificam a interpenetração de fatores etiológicos ditos "ocupacionais" e daqueles "não ocupacionais". Mais: ampliam a compreensão da necessidade da abordagem integral e integrada, e mostram, de forma inquestionável, o quanto ainda falta para que o setor saúde assuma seu papel de executar ou coordenar programas que ajudem a interceptar a "hisória natural" desses desvios da saúde, deixando de se limitar a tratar, internar, ou pagar a conta.

* Os trabalhos de Dohrenwend ${ }^{42,43}$, em psiquiatria social, muito contribuíram neste campo.

** Sobre os problemas relacionados com o trabalho em turnos, vide as contribuições feitas entre nós por Fischer ${ }^{56,57}$. 
MENDES, R. [The impact of occupation on workers' health. I - Morbidity] Rev. Saúde públ., S. Paulo, 22: $311-26,1988$.

ABSTRACT: A review is made to estimate the impact of occupation on workers' health, as part of the rationale with regard to the integration of Occupational Health into the Health Sector. In this first study, based on a critical review of the literature, the repercussions on morbidity are discussed, through the analysis of Brazilian data on occupational accidents, acute occupational intoxications, occupational diseases and other "work-related diseases" such as cardiovascular diseases (hypertension being taken as a model), chronic respiratory diseases, musculoskeletal disorders, (low-back pain serving as a paradigm) mental disorders and stress.

UNITERMS: Occupational diseases. Accidents, occupational. Occupational health. Occupations. Working risks.

\section{REFERÊNCIAS BIBLIOGRÁFICAS}

1. AFACAN, A.S. Sickness absence due do back lesions in coal miners. J. soc. occup. Med., 32:26-31, 1982.

2. ALMEIDA, W.F. \& MARIN, L. Intoxicaçāo por pesticidas na agricultura. Saúde ocup. Seg., 17(3): 111-6, 1982

3. ALMEIDA, W.F. et al. Intoxicaçðes profissionais por pesticidas. In: Mendes, R., ed. Medicina do trabalho: doenças profissionais. São Paulo, Sarvier, 1980. p. 511-69.

4. AMERICAN THORACIC SOCIETY. Definitions and classification of chronic bronchitis, asthma and pulmonary emphysema. Amer. Rev. resp. Dis., 85:762-8, 1962.

5. ANDERSON, J.A.D. Rheumatism in industry: a review. Brit. J. industr. Med., 28:103-21, 1971.

6. ANDERSON, J.A.D. Arthrosis and its relation to work. Scand. J. Wk Environ. Hlth, 10:429-33, 1984.

7. ANDERSON, J.A.D. Shoulder pain and tension neck and their relation to work. Scand. J. Wk Environ. Htlh, 10:435-42, 1984.

8. ANDERSSON, G. Low back pain in industry: epidemiological aspects. Scand. J. rehabil. Med., 11:163-8, 1979.

9. ANDERSSON, G. Epidemiologic aspects of low-back pain in industry. Spine, 6(1):53-60, 1981.

10. ANDRÉN, L. Cardiovascular effects of noise. Acta med. scand., (Suppl. 657):1-45, 1982.

11. ANDRÉN, L, et al. Noise as a contributory factor in the development of elevated arterial pressure. Acta med. scand., 207:493-8, 1980 .

12. ANTTI-POIKA, M. et al. Respiratory diseases in arc welders using basic electrodes. Int. Arch. occup. environ. Hlth, 40(3):225-30, 1977.

13. ARAÚJO, J.W.G. Hipertensão arterial em grupos sócio-ocupacionais de Volta Redonda, RJ. Rio de Janeiro, 1984. [Dissertação de Mestrado - Escola Nacional de Saúde Pública da FIOCRUZ].

14. ARCHER, V.E. \& GILLAM, J.D. Chronic sulfur dioxide, exposure in a smelter. II- Indices of chest disease. J. occup. Med., 20(2):88-95, 1978.

15. ARCHIBALD, R. Success in understanding and preventing coal workers' pneumoconiosis. $J$. occup. Med., 24:452-6, 1982.
16. BELLIBONI, N. et al. Estudo preliminar das dermatoses industriais em São Paulo. Arq. Fac. Hig. S. Paulo, 9(1/2):181-8, 1955.

17. BIERING-SORENSEN, F. A prospective study of low back pain in a general population. I- Occurence, recurrence and aetiology. Scand. J. rehabil. Med., 15:71-9, 1983.

18. BIERING-SORENSEN, F. A prospective study of

low back pain in a general population. II- Location, character, aggravating and relieving factors. Scand. J. rehabil. Med., 15:81-8, 1983.

19. BLEECKER, M.L. Clinical neurotoxicology: detection of neurobehavioral and neurological impairments occurring in the workplace and the environment. Arch. environ. Hth, 39(3):213-8, 1984.

20. BONOMO, I. Reumatismo e sua importância econômico-social na comunidade brasileira. Saúde ocup. Seg., 10(1):27-9, 1975.

21. BRODSKY, C. Long term work stress. Psychosomatics, 25:361-8, 1984.

22. BROWN, J.R. Factors contributing to the development of low back pain in industrial workers. Amer. industr. Hyg. Ass. J., 36:26-31, 1975.

23. BROWN, J.R. Lifting as an industrial hazard. Amer. industr. Hyg. Ass. J., 34:292-7, 1973.

24. CAMPANA, C.L. A problemática vertebral dos cortadores de peças para calçados: sugestões. In: Congresso Nacional de Prevenção de Acidentes do Trabalho, 12\%, Guarapari, 1973. Anais. Rio de Janeiro, DNSHT, 1973. p. 245-9.

25. CAMPANA, C.L. Contribuição para o estudo de alguns dos riscos a que está submetida uma classe de motoristas profissionais. Ribeirão Preto, 1973. [Tese de Doutoramento - Faculdade de Farmácia e Odontologia de Ribeirão Preto da USP].

26. CAMPOS, O. Contribuição ao estudo infortunistico da tuberculose pulmonar e da bronquite crônica. São José dos Campos, 1966. [Tese de LivreDocência - Faculdade de Direito do Vale do Paraíba].

27. CAPLAN, R.D. \& JONES, K.W. Effects of work load, role ambiguity, and type A personality on anxiety, depression, and heart rate. J. appl. Psychol., 60:713-9, 1975 . 
28. CARNEIRO, A.P. \& PEIXOTO, G.M. Contribuiçăo ao estudo epidemiológico da sindrome dolorosa da coluna lombar em trabalhadores da indústria siderúrgica. Rev. bras. Saúde ocup., 9(36):25-8, 1981.

29. CARVALHO, J.J.M. Estudo epidemiológico da pressão arterial em diferentes grupos sociais e profissionais. Rio de Janeiro, 1978. [Dissertação de Mestrado - Faculdade de Medicina da UFRJ].

30. CHAFFIN, D.B. \& PARK, K.S. A longitudinal study of low-back pain as associated with occupational weight lifting factors. Amer. industr. Hyg. Ass. J., 34:513-25, 1973.

31. CIBA GUEST SYMPOSIUM. Terminology, definitions, and classification of chronic pulmonary emphysema and related conditions. Thorax, 14(4):286-99, 1959.

32. COBB, S. \& ROSE, R.M. Hypertension, peptic ulcer, and diabetes in air traffic controllers. $J$. Amer. med. Ass., 224:489-92, 1973.

33. COOPER, C.L. \& MARSHALL, J. Occupational sources of stress: a review of the literature relating to coronary heart disease and mental ill health. $J$. occup. Med., 49:11-28, 1976.

34. COSTA, E.A. A cross-sectional survey of blood pressure in Rio Grande do Sul with special reference to the role of salt. London, 1981. [PhD Thesis University of London]

35. COSTA, E.A. \& KLEIN, C.H. Hipertensão arterial: uma perspectiva sócio-ecológica. Rio de Janeiro, 1980. [Relatório da Pesquisa Epidemiológica sobre Hipertensão Arterial no Rio Grande do Sul. Escola Nacional de Saúde Pública/FIOCRUZ/Secretaria de Saúde do Rio Grande do Sul - mimeografado].

36. COSTA, E.A. \& KLEIN, C.H. Meio urbano e doenças cardiovasculares. Cad. Saúde públ., Rio de Janeiro, 1(3):305-12, 1985.

37. COSTA, J.L.R. Estudo da asbestose no Município de Leme-SP. Campinas, 1983. [Dissertação de Mestrado - Faculdade de Ciências Médicas da UNICAMP].

38. COSTA, J.L.R. \& FERREIRA JR., Y.M. As doenças relacionadas ao asbesto (amianto), Rev. bras. Saúde ocup., 12(47):21-30, 1984.

39. COSTA, J.L.R. et al. Asbesto e doença: introdução ao problema no Brasil. Rev. Ass. med. bras. 29(1/2):18-21, 1983

40. CRUZ FILHO, A. Novos dados sócio-econômicos sobre as doenças reumáticas no Brasil. Rev. bras. Reum., 16:87-90, 1976.

41. DAVIS, P.R. \& SHEPPARD, N.J. Pattern of accident distribution in the telecommunications industry. Brit. J. industr. Med., 37:175-9, 1980.

42. DOHRENWEND, B.P. Social status, stress and psychological symptoms. Amer. J. publ. Hlth, 57:62532, 1967.

43. DOHRENWEND, B.P. \& DOHRENWEND, B.S. Social status and psychological disorders: a casual inquiry. New York, Wiley-Interscience, 1969.

44. DOSMAN, J.A. et al. Chronic bronchitis and decreased forced expiratory flow rates in lifetime nonsmokers grain workers. Amer. Rev. resp. Dis. 121(1):11-6, 1980.

45. FARIA, M.A.M. et al. Alguns aspectos sociais relacionados à ocorrência de acidentes do trabalho em município industrial: o caso de Cubatão. Rev. bras. Saúde ocup., 11(43):25-35, 1983.

46. FARIA, M.A.M. et al. Saúde e trabalho: acidentes de trabalho em Cubatão. Rev. bras. Saúde ocup., 11(42):7-26, 1983.

47. FERREIRA, R.R. \& MENDES, R. Alguns aspectos epidemiológicos dos acidentes de trabalho fatais ocorridos em Campinas, SP, (Brasil), 1972-1978. Rev. Saude públ., S. Paulo, 15:251-62, 1981

48. FERREIRA Jr., Y.M. et al. Aspectos operacionais de um ambulatório universitário de Medicina do Trabalho: a experiência da UNICAMP. Saúde ocup. Seg., 17(1):44-7, 1982.

49. FINE, L.J. \& PETERS, J.M. Respiratory morbidity in rubber workers. I- Prevalence of respiratory symptoms and disease in curing workers. Arch. environ. Hith, 31(1):5-9, 1976.

50. FINOCCHIARO, J. Causas e prevenção das lombalgias em Sào Paulo; estudo de 2836 casos. In: Congresso Nacional de Prevenção de Acidentes do Trabalho, 14., Rio de Janeiro, 1975. Anais. São Paulo, Fundacentro, 1975. p.927-42.

51. FINOCCHIARO, J. Causas e prevençâo dos acidentes e das doenças do trabalho em São Paulo: estudo de 5000 casos. São Paulo, Lex Editora, 1976.

52. FINOCCHIARO, J. Considerações sobre a gravidade do traumatismo craniano na infortunística. Rev. bras. Saúde ocup., 6(22):6-12, 1978.

53. FINOCCHIARO, J. O traumatismo craniano na infortunística: causas, seqüelas e prevenção. In: Congresso Nacional de Prevenção de Acidentes do Trabalho, 16. Porto Alegre, 1977. Anais. São Paulo, Fundacentro/Ministerio do Trabalho, 1977. p 325-7.

54. FINOCCHIARO, J. \& ASSAF, D.L. Infortunística das lombalgias na construção: importância da ergonomia na sua prevenção. Rev. bras. Saúde ocup., 8(29):40-51, 1980.

55. FINOCCHIARO, J. \& ASSAF, D.L. Lombalgias na construção civil e ergonomia. Saúde ocup. Seg., 15(3): 143-55, 1980.

56. FISCHER, F.M. Absenteísmo e acidentes de trabalho entre trabalhadores em turnos de indústrias automobilísticas. São Paulo, 1984. [Tese de Doutoramento - Faculdade de Saúde Pública da USP].

57. FISCHER, F.M. Trabalho em turnos: alguns aspectos econômicos, médicos e sociais. São Paulo, 1980. [Dissertação de Mestrado - Faculdade de Saúde Pública da USP].

58. FRYMOYER, J.W. et al. Risk factors in low-back pain: an epidemiological survey. J. Bone Jt. Surg., 65-A(2):213-8, 1983.

59. GAMBERALE, F. Toxicologia comportamental: um novo campo de pesquisa em saúde ocupacional. Rev. bras. Saude ocup., 5(18):47-51, 1977.

60. GARDELL, B. Technology, alienation and mental health. Acta sociol., 19:83-94, 1976.

61. GARFIELD, J. O trabalho alienado, stress e doença coronariana. In: Nunes, E.D., org. Medicina social: aspectos históricos e teóricos. São Paulo, Global, 1983. p. 159-79.

62. GIBSON, E.S. et al. Incidence of low back pain and pre-placement x-ray screening. $J$. occup. Med., 22:515-9, 1980.

63. GOBBATO, F. et al. L'esposizione a vibrazioni, trasmesse al sistema mano-braccio, può rappresentare un fattore di rischio per l'ipertensione? Med. $d$. La voro, $72: 389-98,1981$

64. GOMES, E.R. Condiçôes de higiene do trabalho e incidência de cromoergopatias em trabalhadores de galvanoplastias sindicalizadas do Estado de São Paulo. São Paulo, 1970. [Dissertação de Mestrado - Faculdade de Saúde Pública da USP].

65. GOMES, E.R. Incidence of chromium-induced lesions among electroplating workers in Brazil. Industr. Med. Surg., 41(12):21-5, 1972. 
66. GOMES, J.R. Saúde do trabalhädor em operaçōes de soldagem. Såo Paulo, 1984. [Tese de LivreDocência - Faculdade de Saúde Pública da USP].

67. GONDIM, P.M. \& LATGE, M. Problemas de higiene industrial no Estado do Rio de Janeiro. Rev. Serv. esp. Saúde públ., 10(1/2):565-606, 1959.

68. HIGGINS, I.T.T. Chronic respiratory disease in mining communities. Ann. N. Y. Acad. Sci., 200:197. $210,1972$.

69. HIGGINS, I.T.T. et al. Population studies of chronic respiratory disease: a comparison of miners, foundryworkers, and others in Staveley, Derbyshire. Brit. $J$. industr. Med., 16:255-68, 1959.

70. HUNGRIA FILHO, J.S. A perícia médica nos casos de dores lombares. Arq. Hosp. S. Casa S. Paulo, 11(1/4):23-35, 1965.

71. IVANCEVICH, J.M. \& MATTESON, M.T. Stress and work: a managerial perspective. Dallas, Scott, Foresman, 1980.

72. JOHNSON, B.L. \& ANGER, W.K. Behavioral toxicology. In: Rom, W.N., ed. Environmental and occupational medicine. Boston, Little, Brown, 1983. p. $329-50$.

73. JUNQUEIRA, J.A. A saúde ocupacional no armazenamento do café. Saúde ocup. Seg., 6(3):74-80, 1971.

74. KALACIC, I. Chronic nonspecific lung disease in cement workers. Arch. environ. Hlth, 26(2):78-83, 1973.

75. KALACIC, I. Early detection of expiratory airflow obstruction in cement workers. Arch. environ. Hlth, 29(9):147-9, 1974.

76. KALACIC, I. Ventilatory lung function in cement workers. Arch. environ. Hlth, 26(2):84-5, 1973.

77. KASL, S.V. \& COBB, S. Blood pressure changes in men undergoing job loss: a preliminary report. Psychosom. Med., 2:19-38, 1970.

78. KASL, S.V. \& COBB, S. Psychological and social stresses in the workplace. In: Levy, B.S. \& Wegman, D.H., ed. Occupational health: recognizing and preventing work-related disease. Boston, Little, Brown, 1983. p. 251-63.

79. KAZAVA, K.H. et al. Consideraçōes sobre a casuistica do Ambulatório de Medicina do Trabalho da Faculdade de Ciências Médicas da UNICAMP. Rev. bras. Saúde ocup., 10(39):7-11, 1982.

80. KELSEY, J.L. \& HARDY, R.J. Driving of motor vehicles as a risk factor for acute herniated lumbar intervertebral disc. Amer. J. Epidem., 103:63-73, 1975.

81. KELSEY, J.L. et al. The impact of musculoskeletal disorders on the population of the United States. $J$. Bone Jt. Surg., 61-A(7):959-64, 1979.

82. KLEIN, C.H. Hipertensão arterial de estratos geo-econômicos do Rio Grande do Sul. Rio de Janeiro, 1981. [Dissertação de Mestrado - Escola Nacional de Saúde Pública da FIOCRUZ].

83. KLEIN, C.H. \& ARAÚJO, J.W.G. Fumo, bebida alcoólica, migração, instrução, ocupação, agregação familiar e pressão arterial em Volta Redonda. Cad. Saúde públ., Rio de Janeiro. 1(2):160-76, 1985.

84. KLOETZEL, K. et al. Relationship between hypertension and prolonged exposure to heat. J. occup. Med., 15:878-80, 1973.

85. KNOPLICH, J. A importância das dores na coluna na prática médica e na indústria. Rev. bras. Saúde осир., 9(36):71-4, 1981.

86. KURPPA, K. et al. Peritendinitis and tenosynovitis: a review. Scand. J. Wh Environ. Hlth, 5(Suppl. 3):19-24, 1979.
87. LAUAR, E.D. et al. Implantaçăo de programa de Saúde Ocupacional no ambulatório do Hospital das Clínicas da UFMG. Rev. bras. Saúde ocup., 12(48):71-4, 1984.

88. LAURENTI, R. Doenças respiratórias como causa de morte no Município de São Paulo, SP (Brasil). Rev. Saúde públ., S. Paulo, 15:353-63, 1981.

89. LESSA, I. Doenças crônico-degenerativas. In: Rouquayrol, M.Z., ed. Epidemiologia \& saúde. Rio de Janeiro, Medsi, 1986. p. 331-42.

90. LEVI, L. Stress. In: Encyclopaedia of occupational health and safety. $3^{\text {rd }}$ ed. Geneva, International Labour Office. 1983, v. 2, p. 2106-11.

91. LEVI, L. Work, stress and health. Scand. J.Wk Environ. Hlth, 10:495-500, 1984.

92. LOPES, R.M. Acidentes do trabalho na mão-de-obra volante empregada na agricultura (bóias-frias), Botucatu, SP. São Paulo, 1983. [Dissertação de Mestrado - Faculdade de Medicina da USP].

93. LOPES, R.M. Acidentes do trabalho na agricultura, Botucatu, SP. Rev. bras. Saúde ocup., 10(39):1217, 1982.

94. LOPES, R.M. Acidentes do trabalho na zona canavieira de Lençóis Paulista. Rev. bras. Saúde ocup., 10(37):42-5, 1982.

95. MAGORA, A. Investigation of the relation between low back pain and occupation. II - Work history. Industr. Med. Surg., 39:504-10, 1970.

96. MAGORA, A. Investigation of the relation between low back pain and occupation. III - Physical requirements: sitting, standing and weight lifting. Industr. Med. Surg., 41:5-9, 1972.

97. MAGORA, A. Investigation of the relation between low back pain and occupation. IV - Physical requirements: bending, rotation, reaching and sudden maximal effort. Scand. J. rehabil. Med., 5:186-90, 1973.

98. MALUF, U.M.M. et al. Otimização ergonômica nos tratos culturais na lavoura de cana-de-açúcar. Rev. bras. Saúde ocup., 11(44):18-28, 1983.

99. MEDICAL RESEARCH COUNCIL. Committee on the Aetiology of Chronic Bronchitis. Definition and classification of chronic bronchitis for clinical and epidemiological purposes. Lancet, 1:775-9, 1965.

100. MEDINA, M.C.G. A aposentadoria por invalidez no Brasil. São Paulo, 1986. [Dissertação de Mestrado - Faculdade de Medicina da USP].

101. MENDES, R. Epidemiologia da silicose na Região Sudeste do Brasil: contribuição para seu estudo através de inquérito em pacientes internados em hospitais de tisiologia. São Paulo, 1978. [Tese de Doutoramento - Faculdade de Saúde Pública da USP].

102. MENDES, R. Estudo epidemilógico sobre a silicose pulmonar na Região Sudeste do Brasil, através de inquérito em pacientes internados em hospitais de tisiologia. Rev.. Saúde públ., S. Paulo, 13:7-19, 1979.

103. MENDES, R. Importância das pequenas empresas industriais no problema de acidentes do trabalho em São Paulo. São Paulo, 1975. [Dissertação de Mestrado - Faculdade de Saúde Pública da USP].

104. MENDES, R. Importância das pequenas empresas industriais no problema de acidentes do trabalho em São Paulo. Rev. Saúde Públ., S. Paulo, 10:315-25, 1976.

105. MORGAN, W.K.C. Industrial bronchitis. Brit. J. industr. Med., 35:285-91, 1978. 
106. MORGAN, W.K.C. Industrial bronchitis and other nonspecific conditions affecting the airways. In: Morgan, W.K.C. \& Seaton, A. Occupational lung diseases. 2nd ed. Philadelphia, Saunders, 1984. p. $521-40$.

107. MORITA, S.M. et al. Intoxicação por inseticidas organofosforados. Rev. bras. Saúde ocup., 7(28): 70-2, 1979.

108. MORRONE, L.C. Epidemiologia da silicose no Estado de São Paulo. São Paulo, 1979. [Dissertação de Mestrado - Faculdade de Saúde Pública da USP].

109. MUSTACCHI, P. The interface of the work environment and hypertension. Med. Clin. North Amer., 61:531-45, 1977.

110. NOGUÉRA, D.P. et al. Acidentes graves do trabalho na capital do Estado de São Paulo (Brasil). Rev. Saúde públ., S. Paulo, 15:3-13, 1981.

111 NOGUEIRA, D.P. et al. Asbestose no Brasil: um risco ignorado. Rev. Saúde públ., S. Paulo, 9:427$32,1975$.

112. NOGUEIRA, D.P. et al. Ocorrência da silicose entre trabalhadores da indústria cerâmica da cidade de Jundiaí, SP (Brasil). Rev. Saúde públ., S. Paulo, 15:263-71, 1981.

113. OLIVAN FILHO, A. et al. Estudo epidemiológico dos acidentes do trabalho fatais na Grande São Paulo, no periodo de 1979 a 1982. Rev. bras. Saúde ocup., 12(46):7-13, 1984.

114. OXHOJ, $\mathrm{H}$. et al. Effects of electric arc welding on ventilatory lung function. Arch, environ. Hlth, 24:211-7, 1979.

115. PEIXOTO, G.M. Contribuição à investigação e prevenção das lombalgias por acidentes do trabalho na indústria siderúrgica. Rev. bras. Clín. Terap., 3:423-6, 1974.

116. PEREIRA, C.A. Surdez profissional em trabalhadores metalúrgicos: estudo epidemiológico em uma indústria da Grande São Paulo. São Paulo, 1978. [Dissertação de Mestrado - Faculdade de Saúde Pública da USP].

117. REPKO, J.D. \& CORUM, C.R. Avaliação retrospectiva crítica das sequelas neurológicas e comportamentais em razão da absorção de chumbo inorgânico. Rev. bras. Saúde ocup., 12(45):7-41, 1984.

118. RIBEIRO, H.P. \& LACAZ, F.A.C., org. De que adoecem e morrem os trabalhadores. São Paulo, DIESAT, 1985.

119. RIBEIRO, M.D. et al. Hypertension and economic activities in São Paulo, Brazil. Hypertension, 3(Suppl 2): 233-7, 1981 .

120. ROSE, V.E. Reliability and utilization of occupational disease data. Cincinnati, Ohio, National Institute for Occupational Safety and Health, 1977. (DHEW (NIOSH) Publication n? 77-189).

121. ROWE, M.L. Low back pain in industry: a position paper. J. occup. Med., 11(4):161-9, 1969.

122. ROWE, M.L. Low back disability in industry: updated position. J. occup. Med., 3(10): 476-8, 1971 .

123. SAMARA, A.M. Reumatismo: um desafio à economia brasileira. Rev. Ass. med. bras., 23(2): 71-2, 1977.

124. SANDOVAL, A.F. Estudo de tendosinovites em indústria de sapatos. Saúde ocup. Seg., 16(6): 224-8, 1981.
125. SCHILLING, R.S.F. More effective prevention in occupational health practice? J. Soc. occup. Med., 34: 71-9, 1984.

126. SCHNALL, P.L. \& KERN, R. Hypertension in American society: an introduction to historical materialist epidemiology. In: Conrad, P. \& Kern, R., ed. The sociology of health and illness: critical perspectives. New York, St. Martin's Press, 1981. p.97. 122.

127. SEGRE, M. \& PÁSCOA, M.P. Acidentes do trabalho incapacitantes e mortals em região pouco industrializada: Botucatu-SP. In: Congresso Nacional de Prevenção de Acidentes do Trabalho, 13ㅇ, São Paulo, 1974. Anais. São Paulo, Fundacentro, 1974. p.389-408.

128. SERVIÇO SOCIAL DA INDÚSTRIA (SESI). Inquérito preliminar de higiene industrial no Municipio de São Paulo. São Paulo, 1955. [Mimeografado].

129. SINAI, N. apud CHAVES, M.M. Odontologia sanitária. Washingon, D.C., Organización Panamericana de la Salud, 1962. (OPS - Publicacion científica, $63)$.

130. SIQUEIRA, M.L. et al. Diagnóstico dos problemas ecotoxicológicos causados pelo uso de defensivos agrícolas no Estado do Paraná. Rev. bras. Saúde ocup., 11(44): 7-17, 1983.

131. STUBBS, D.A. \& NICHOLSON, A.S. Manual handling and back injuries in the construction industry: an investigation. J. occup. Accid., 2: 17990, 1979.

132. TANCREDI, F.B., rel. Saúde mental. In: Seminário sobre Situação de Saúde nas áreas Metropolitanas Brasileiras, São Paulo, 1975. Anais. São Paulo, Faculdade de Saúde Pública da USP, 1976. p.163-8.

133. TEIXEIRA, J.W. Acidentes do trabalho com óbitos: estudo da mortalidade ocorrida em Santa Catarina no ano de 1981. Rev. bras. Saúde ocup., 10(40): 31 . $5,1982$.

134. TIMIO, M. Clases sociales y enfermedad: introducción a una epidemiología diferencial. México, Nueva Imagem, 1980.

135. TRAPE, A.Z. et al. Projeto de vigilância epidemiológica em ecotoxicologia de pesticidas. Rev. bras. Saúde ocup., 12(47): 12-20, 1984.

136. TROUP, J.D.G. Driver's back pain and its prevention: a review of the postural, vibratory and muscular factors, together with the problem of transmitted road-shock. Appl. Ergon., 9: 207-14. 1978.

137. TROUP, J.D.G. Causes, prediction and prevention of back pain at work. Scand. J. Wk Environ. Hlth, 10: $419-28,1984$.

138. USA. Department of Health and Human Services. Office on Smoking and Health. The health consequences of smoking. Cancer and chronic lung disease in the workplace: a report to the surgeon general. Rockville, Maryland, 1985. (DHHS (PHS) 85. 50207).

139. VAARANEN, V. Occupational diseases reported to Finnish Register of Occupational Diseases in 19641974. [English Summary]. Helsinki, 1977. [Doctoral Dissertation - Institute of Occupational Health].

140. VAARANEN, V. et al. Occupational diseases in Finland in 1998. Helsinki, Institute of Occupacional Health, 1983. (Reviews, 8). 
141. VIEIRA, H.R.A. et al. Contribuiçăo ao conhecimento dos acidentes do trabalho rural no Estado do $\mathrm{Pa}$ raná. Rev. bras. Saúde ocup., 11(44): 50-66, 1983.

142. WALKER, D.D. et al. Bronchitis in men employed in the coke industry. Brit. J. industr. Med., 28: 35863, 1971.

143. WESTERHOLM, P. Silicosis: observations on a case register. Scand. J. Wk Environ. Hlth, 6(Suppl. 2): $1-86,1980$.

144. WORLD HEALTH ORGANIZATION. Expert Committee on Arterial Hypertension, Geneva, 1978. Report. Geneva, 1978. (Techn. Rep. Ser., 628).

145. WORLD HEALTH ORGANIZATION. Expert Committee on Identification and Control of Workrelated Diseases, Geneva, 1983. Report. Geneva, 1985. (Techn. Rep. Ser., 714).
146. WORLD HEALTH ORGANIZATION. Scientific Group on Primary Prevention of Essential Hypertension, Geneva, 1982. Report. Geneva, 1983. (Techn. Rep. Ser., 686).

147. YELIN, C. et al. Toward an epidemiology of work disability. Milbank mem. Fd Quart., 58:386-415, 1980.

148. YU, T. et al. Low back pain in industry: an old problem revisited. J. occup. Med., 26(7): S17-24, 1984.

Recebido para publicação em 18/1/1988 Aprovado para publicação em 15/4/1988 